\title{
Moralidade e Homicídio: Um Estudo sobre a Motivação do Transgressor
}

\section{Morality and Homicide: A Study on the Motivation of the Transgressor}

\author{
Luciana Souza Borges*, Heloisa Moulin de Alencar \\ Universidade Federal do Espírito Santo, Vitória, Brasil
}

\begin{abstract}
Resumo
Investigamos os juízos de representação da realidade (JRR) e de valor moral (JVM) de 20 homens homicidas (30 a 49 anos), acerca da razão do crime, à época do homicídio e no momento atual. Realizamos entrevistas individuais e verificamos que: o JRR mais apontado, no presente e no passado, foi a agressão física sofrida, justificada no presente principalmente pelo fato de o agressor ter-se sentido humilhado e, no passado, pelo fato de ter querido vingar-se e pelas características próprias, dele ou da vítima; o JVM mais mencionado no passado foi o de que as razões estavam certas, devido a características dos entrevistados ou das vítimas, pelas humilhações sofridas ou porque precisavam defender uma vida, ao passo que no presente o juízo mais citado pelos entrevistados foi o de que estavam errados os motivos, em face das conseqüências negativas do crime para eles e dos argumentos religiosos.
\end{abstract}

Palavras-chave: Moralidade; homicídio; motivação.

\begin{abstract}
We investigated the judgment of representation of reality (JRR), and the judgment of moral value (JVM) of 20 homicidal subjects ( 30 to 49 ) as to the reasons of the crime, at the time of the homicide and at the present moment. Individual interviews were carried out. We verified that the most indicated JRR, in the present and in the past, was the physical aggression suffered by the aggressor, justified in the present because the aggressor felt humiliated and, in the past, for having wished to take revenge due to his or the victim's characteristics; the most mentioned JVM in the past was that that their reasons were right due to the characteristics of the interviewees or those of the victims, for the humiliations suffered or because they needed to defend a life, whereas in the present, the most cited judgment was that their motives were wrong, in face of the negative consequences, and religious arguments.
\end{abstract}

Keywords: Morality; homicide; motivation.

Vários foram os autores que se debruçaram sobre questões atinentes à moralidade humana. No entanto, interessam a este trabalho, em particular, as fundamentações firmadas por Piaget (1932/1994). Em decorrência dessa opção teórica, gostaríamos de assinalar, de passagem, a respeito de como Kant (1785/1980, 1788/1994) parece ter influenciado fundamentalmente os trabalhos desenvolvidos na área da Psicologia da moralidade, com destaque para as duas tendências morais, a heteronomia e a autonomia. Foi assim que, no início do século XX, o epistemólogo suíço Jean Piaget (1932/1994) começou a estudar a construção da moralidade em crianças.

Para este autor, o desenvolvimento moral segue uma evolução que passa da moral heterônoma (a consciência

\footnotetext{
* Endereço para correspondência: Curso de Graduação em Psicologia da Faculdade Salesiana de Vitória, Av. Vitória, 950, Forte São João, Vitória, ES, 29017 950. E-mail: lucianasouzaborges@terra.com.br ou lborges@salesiano.com.br Esse estudo faz parte do trabalho de dissertação de mestrado da primeira autora sob orientação da segunda, que agradecem à Fundação Coordenação de Aperfeicoamento de Pessoal de Nível Superior (CAPES) pelo apoio financeiro concedido. Aproveitam a oportunidade para agradecer também a todos aqueles que participaram da pesquisa, e, especialmente, ao Programa de Pós-Graduação em Psicologia (PPGP) da Universidade Federal do Espírito Santo (UFES).
}

moral é externa, imposta pelas autoridades) para a moral autônoma (a consciência moral é individual), sendo que, antes dessas duas etapas, temos o que foi denominado pelo autor por anomia, ou seja, ausência de regras. Vemos que, nesse processo de evolução de uma moral heterônoma para uma autônoma, o tipo de respeito que o sujeito estabelece para com os demais é o que fará a diferença, pois passará de um respeito unilateral, pelo qual deverá obedecer ao outro, a um respeito que deverá ser mútuo.

Assim, o processo de socialização tem um valor peculiar na teoria piagetiana, especificamente quando tratamos da moralidade, pois é por meio das relações sociais vivenciadas que chegaremos a um sujeito autônomo, aquele que conseguirá refletir eficazmente sobre a diversidade de pontos de vista de uma dada sociedade. Nessa medida, as interações sociais são valorizadas por Piaget pela via da moral e é nesse sentido que influenciam o desenvolvimento dos sujeitos (La Taille, 1992). Portanto, ensina La Taille que a finalidade da passagem da heteronomia para a autonomia é inserir o sujeito no campo da moralidade, durante seu processo de socialização, pois, na medida em que se estabelece uma condição de igualdade entre todos, no último estágio, acaba-se por defender uma condição democrática de convívio 
social, a qual se faz necessária à própria construção da personalidade do sujeito. Para Piaget (1932/1994), um indivíduo que se desenvolve moralmente, ou seja, que constrói sua autonomia, é aquele capaz de seguir determinadas regras, não por medo de infringi-las, mas pela crença de que será o melhor para si e para a sociedade. A moralidade envolve, portanto, um conjunto de normas vinculadas à necessidade de convivência interpessoal. Mas, para que se alcance um convívio adequado, é necessário que a regra faça sentido para os sujeitos nela implicados. Na convivência cotidiana, a moralidade ser-nos-á ensinada a todo momento, mesmo sem intenção, tendo em vista que as mensagens e os valores são transmitidos constantemente nas inter-relações sociais.

Ao circunscrever o estudo do crime de homicídio doloso ao campo da moralidade e, portanto, inserido nas relações sociais, tivemos necessariamente que relacioná-lo ao contex to genérico da violência e ao da criminalidade, em particular, no panorama da sociedade brasileira. Dessa forma, alguns autores (Velho, 1996b, Zaluar, 1994), explicam o crescente estado de violência no Brasil, por meio da perda de uma sociabilidade civilizada, minimamente considerada, que se deu ao longo dos anos, determinada, portanto, historicamente. Consideram que o que se perdeu nesse período foi uma forma de contrato social entre as diferentes classes, que garantiria o valor da cidadania. Sem isso, ficamos à mercê da exclusão social e dos mais variados tipos de violência, tendo como resultado, em todos os ramos da vida social, manifestações de desrespeito, desconsideração e falta de compromisso ético para com os parceiros sociais. No entanto, ressaltamos o fato de a violência poder residir nas próprias regras estabelecidas, antes mesmo de estar com aquele que as transgride, visão estritamente jurídica. Assim, Chauí (1980) e Velho (1996a), não justificam a violência como conseqüência do estado de empobrecimento da população, mas vinculam-na à perda de referenciais éticos, própria de um novo modus vivendi, própria de uma época social dita pós-moderna.

Com relação à criminalidade, em particular, outros autores (Adorno, 1998; Zaluar, 1996) ressaltam que as causas atuais também se assentam em uma falha da esfera da moralidade, pois é em meio a uma fragilidade das regras sociais e morais, que o sujeito deixa de levar o outro em consideração e comete uma ação transgressora, abrindo um hiato entre a imposição moral (em nosso caso 'não matar'), e a ação infratora. É nesse campo que se insere o crime de homicídio doloso. Esclarecemos que doloso é o crime praticado por aquele que deseja, espontaneamente, cometê-lo ou assume o risco de fazê-lo. Diferente é o crime culposo, praticado por quem não tem intenção de cometê-lo, mas o pratica por imprudência, imperícia ou negligência, nos termos da lei penal (Brasil, 1997) vigente no País. O homicídio é uma forma de violência que atesta contra um dos valores mais prestigiados da humanidade: a vida. Constatamos, juntamente com Mello Jorge, Gawryszewski e Latorre (1997), que na década de 1990 os homicídios passam a ocupar o $1^{\circ}$ lugar, sobretudo nas regiões Norte e Sudeste do País, na classificação de mortes por causas externas. O Brasil revela números extraordinários de mortes, em especial de jovens, em que se destaca um dos componentes do dolo (a intencionalidade) na prática desse delito. Com relação à distribuição geográfica, a Grande Vitória, no estado do Espírito Santo, é apontada nessa análise como pertencente ao grupo de localidades com mais elevada taxa de causas externas (não naturais) para a explicação de suas mortes. Quanto ao fator homicídio, particularmente, Vitória apresentou um aumento de $454 \%$ em seus coeficientes, no período estudado pelos autores, revelando-se a região com o índice mais elevado de incidência desse crime.

Face a este supereminente índice do crime de homicídio e a vastidão do campo de estudo da moralidade, interessounos, em particular, abordar um tema específico, o da honra, por considerá-lo fundamental para o estudo do homicídio doloso. La Taille (1997), visando a ampliar os estudos acerca do desenvolvimento do juízo moral para além do que foi inicialmente proposto por Piaget (1932/1994), chama-nos a atenção para o valor que damos ao "olhar do outro" (p. 226). Para La Taille (2002), o conceito que melhor abordará essa discussão é o da honra, tendo em vista que ele associa a vergonha à moralidade. $\mathrm{O}$ autor distingue vergonha de humilhação: embora esteja presente um sentimento de rebaixamento, experienciado tanto pela pessoa que sente vergonha quanto por aquela que se sente humilhada, na vergonha a imagem negativa que o outro faz de mim acaba por ser a minha também, ocasionando esse sentimento. No caso da humilhação, diferentemente, apesar de o outro fazer um juízo negativo de mim, eu não concordo com esse juízo, ou seja, o juízo que eu mesmo faço de mim é diferente e eu não o modifico diante do outro. Neste último caso, La Taille (2002) explica que estamos diante de um tipo peculiar de vergonha, chamada humilhação, pela qual a imagem negativa imposta pelo outro não será necessariamente aceita por mim. Neste sentido, Ades (1999) ressalta que as reações que freqüentemente acompanham aquele que sofre uma humilhação são ". . . a raiva e o desejo de revidar, dentro ou fora de um código de honra" (p. 44), ao passo que aquele que sente vergonha moral reage com desejos de fugir (esconder-se) da situação constrangedora.

Segundo La Taille (2002), a honra tem por objetivo proteger uma esfera íntima, própria do sujeito e, portanto, individual, que é o seu respeito próprio e aquilo que o faz ser bem visto por aqueles com quem convive. Há várias formas de se atingir essa dignidade, como um olhar, um insulto, uma crítica etc. Quando alguém percebe sua honra ameaçada, sua reação é a de defendê-la, pois, caso contrário, poderá sentir vergonha e/ ou humilhação. Portanto, é o fato de alguém sentir-se ofendido que o faz reagir em defesa de sua honra.

A revisão de literatura permitiu-nos traçar uma distinção entre o que podemos chamar de honra exterior e honra interior (Febvre, 1998) ou entre um aspecto objetivo e outro subjetivo da honra (Aranha, 1995). Em suma, a honra exterior ou o aspecto objetivo da honra trata de juízos que vêm de fora do sujeito, ou seja, é a reputação que cada um 
de nós tem na sociedade. A honra interior ou o aspecto subjetivo da honra, por outro lado, diz respeito àquilo que cada um de nós pensa de si, o juízo que temos de nós mesmos, ou seja, o sentimento de dignidade e o valor pessoal de cada um. Ades (1999) defende a importância de ambos os aspectos da honra, tendo em vista que tanto o juízo que fazemos de nós mesmos quanto o juízo que os outros fazem de nós serão fundamentais para compreendermos essa temática. Febvre (1998), por sua vez, estabelece uma relação entre a honra interior e a exterior, ao argumentar que “. . . honra é o resultado de uma pressão, aceita, do grupo, da coletividade sobre uma ou várias consciências individuais” (p. 65).

Por fim, ressaltemos os aspectos que a honra pode assumir, como assim denominou La Taille (2002): "pela honra" ou "com honra" (p. 155). De modo geral, agir "em nome da honra' ou 'pela honra' representa uma perda de sentido moral, caso a ação não se dê 'com honra', porque somente neste último caso as regras são respeitadas, e a honra vincula-se a virtudes tais como a coragem, a igualdade e a fidelidade. No caso de uma ação homicida, vemos que a conduta do transgressor revela-se desonrosa, isto é, moralmente nula de virtude. Agir 'com honra', portanto, eleva o sujeito a uma condição em que passa a ser moralmente virtuoso e, ao contrário, o agir 'pela honra' caracteriza um sujeito que age de forma desonrosa, não moral.

Tendo em vista que os participantes deste estudo cometeram o homicídio há alguns anos, tal situação nos impede de realizar uma investigação direta e próxima acerca daquilo que ensejou essa ação criminosa, que são as circunstâncias que nos interessam sobre o fato ocorrido no passado. No entanto, podemos conhecer como esses participantes estabelecem seus juízos sobre o homicídio cometido, tanto de representação da realidade (JRR) quanto de valor moral (JVM). Conforme Alencar (2003), quando falamos em juízo de representação da realidade (JRR) e em juízo de valor moral (JVM), remetemo-nos a diferentes aspectos de uma mesma situação, que fazem referência a "o que se é" e "o que deve ser” (p. 29), respectivamente. Embora as duas condições nos levem a juízos, não podemos considerá-las, de forma idêntica, juízos de valor, segundo a autora. Ademais, aqueles dois juízos não são necessariamente coincidentes, pois o participante pode responder de uma determinada forma para 'o que se é' e de maneira oposta a 'o que deve ser'.

No juízo de representação da realidade (JRR) da motivação interessa-nos o motivo ('o que é') que o participante teve para ter cometido o homicídio, enquanto no juízo de valor moral (JVM) da motivação buscamos conhecer sua aprovação ('o que deve ser') dessa motivação e, em caso de desaprovação dessa motivação, se haveria outros motivos que o levariam à mesma ação. Enfim, são várias as possibilidades para a motivação da ação, quando analisamos o juízo de representação da realidade (JRR) e o juízo de valor moral (JVM). Alencar (2003), ao discutir a diferença de conceito entre os dois juízos, lança mão de algumas considerações feitas por Kant, acerca do estudo da moralidade, pois para ele uma ação só é moral se ocorrer por dever. Assim, o ser e o dever-ser estão, para a autora, intimamente relacio- nados aos conceitos de imperativo hipotético e categórico de Kant, respectivamente. Alencar conclui, no esteio da moral kantiana, que o imperativo hipotético refere um princípio de ação que é subjetivo, que diz respeito ao sujeito, às suas próprias condições e é, portanto, o princípio que determina suas ações (juízo de representação da realidade - JRR). No caso do imperativo categórico, a ação do sujeito é regida por um princípio que é objetivo, ou seja, que vale para todos, sendo, portanto, um imperativo pelo qual todos deveriam agir, tendo em vista o respeito à lei (juízo de valor moral - JVM)

Considerando o fato de que os sujeitos que cometem um homicídio doloso estão transgredindo uma regra de convívio social e de valor moral (o direito à vida), interessou-nos investigar, especificamente, como raciocinam sujeitos homicidas a respeito da razão do crime que cometeram (motivação). Objetivamos, portanto, caracterizar a atual compreensão dessa realidade transgressora vivida pelo sujeito, a partir de seu próprio ponto de vista, avaliando se o seu juízo de representação da realidade (JRR) e o seu juízo de valor moral (JVM) diferem quando tratamos do passado e do presente.

\section{Método}

\section{Participantes}

Nossa amostra compôs-se de 20 (vinte) participantes do sexo masculino, com idade variando entre 30 e 49 anos, que, na ocasião da coleta de dados, cumpriam pena em regime de liberdade condicional na Vara de Execuções Penais (VEP) de Vitória por terem sido condenados pela prática do crime de homicídio doloso. Esta delimitação foi precedida por uma pesquisa documental, a partir dos arquivos de atendimento periódico do Serviço Social e Psicológico (SSP), setor da VEP de Vitória responsável por seu acompanhamento, a fim de identificar os prontuários daqueles que haviam sido condenados por homicídio doloso, identificados, ao final, em número de 65. Obtivemos, então, uma gama de informações acerca desses sujeitos e, após análise do material encontrado, delimitamos a amostra por dois critérios, gênero e faixa etária, tendo em vista que, de acordo com esse levantamento inicial, 93\% eram homens e $70 \%$ deles estavam compreendidos na faixa de idade entre $30 \mathrm{e}$ 49 anos.

\section{Instrumentos e Procedimentos}

Utilizamos uma entrevista semi-estruturada, a partir dos fundamentos do método clínico, originalmente proposto por Piaget (1926/s.d., 1932/1994). A partir dele, de acordo com as respostas de cada sujeito, fizemos as perguntas subseqüentes, tendo em vista o seguinte roteiro de questões abertas sobre os juízos, de representação da realidade e de valor moral, da motivação para o crime de homicídio:

1. Hoje (naquela época), quais os motivos que você teve para cometer o homicídio? Por quê?

2. Hoje (naquela época), como você julga (julgou) os motivos que teve para cometer o homicídio? Por quê? 
3. (Em caso de desaprovação do motivo) Hoje (naquela época) você considera (considerou) que existiam outros motivos que poderiam justificar o homicídio que cometeu? Por quê?

4. (Em caso de haver outros motivos) Quais? Por quê?

Os participantes foram entrevistados individualmente e as questões formuladas em relação tanto ao presente quanto ao passado. Como ex emplo da primeira questão, temos: (a) Presente-Hoje, quais os motivos que você teve para cometer o homicídio?; (b) Passado - Naquela época, quais os motivos que você teve para cometer o homicídio? E assim, sucessivamente. Ressaltamos que a primeira questão refere-se ao juízo de representação da realidade (JRR) e as demais tratam do juízo de valor moral (JVM).

Usamos o método clínico em sua forma puramente verbal (Delval, 2002) e justificamos esta opção a partir de três fatores: (a) em função da idade dos sujeitos, por serem adultos e, conseqüentemente, já possuírem linguagem estabelecida; (b) pela baixa escolaridade dos participantes e possíveis dificuldades de leitura e escrita e (c) pelo tipo de fenômeno aqui estudado, pois o crime já ocorreu e está inacessível no mundo natural (embora possa estar presente no pensamento de cada participante), somente nos sendo possível, portanto, investigar sua representação.
Priorizamos a análise qualitativa dos resultados encontrados, sem prejuízo de uma referência quantitativa para eles, em termos percentuais, quando estabelecemos algumas relações entre as informações encontradas. Contamos com a colaboração de uma 'juíza independente' que ocupou a função de assistente em nosso trabalho na fase de categorização dos dados. Estabelecemos, então, um "acordo interjuízes” (Delval, 2002, p. 165) e obtivemos um índice de concordância próximo a $98 \%$ no processo final da categorização dos dados. O programa estatístico SPSS for Windows (1999) foi aplicado aos resultados, a fim de primeiramente poder gerar o índice de concordância entre as planilhas da pesquisadora e da assistente e, posteriormente, realizar uma análise desses dados, por meio do estudo da freqüência de todas as informações encontradas. Passemos então aos principais resultados encontrados em nossa pesquisa.

\section{Resultados e Discussão}

Sobre as razões para terem cometido um homicídio (JRR), os 20 entrevistados alegaram um total de 56 respostas no presente, que foram agrupadas em oito possíveis motivos, para os quais apresentaram as justificativas que se encontram na legenda, como podemos observar na Tabela 1.

Tabela 1

Distribuição das Respostas e das Justificativas dos Participantes para o JRR da Motivação no Presente

\begin{tabular}{|c|c|c|c|c|c|c|c|c|c|c|}
\hline \multirow{2}{*}{ Motivos do crime } & \multicolumn{9}{|c|}{ Justificativas } & \multirow{2}{*}{$\begin{array}{l}\text { Total de } \\
\text { respostas }\end{array}$} \\
\hline & $\mathrm{J}_{1}$ & $\mathrm{~J} 2$ & $\mathrm{~J} 3$ & $\mathrm{~J} 4$ & $\mathrm{~J} 5$ & J6 & $\mathrm{J} 7$ & $\mathrm{~J} 8$ & J9 & \\
\hline 1. A agressão física que sofreu & $\begin{array}{c}1 \\
5,9 \%\end{array}$ & - & $\begin{array}{c}1 \\
5,9 \%\end{array}$ & $\begin{array}{c}7 \\
41,2 \%\end{array}$ & $\begin{array}{c}3 \\
17,6 \%\end{array}$ & $\begin{array}{c}2 \\
11,8 \%\end{array}$ & - & $\begin{array}{c}1 \\
5,9 \%\end{array}$ & $\begin{array}{c}2 \\
11,8 \%\end{array}$ & $\begin{array}{c}17 \\
30,4 \%\end{array}$ \\
\hline 2. A defesa da própria vida ou de familiares & $\begin{array}{c}8 \\
66,7 \%\end{array}$ & - & $\begin{array}{c}1 \\
8,3 \%\end{array}$ & - & - & $\begin{array}{c}1 \\
8,3 \%\end{array}$ & $\begin{array}{c}1 \\
8,3 \%\end{array}$ & - & $\begin{array}{c}1 \\
8,3 \%\end{array}$ & $\begin{array}{c}12 \\
21,4 \%\end{array}$ \\
\hline 3. A atitude de um familiar & - & - & $\begin{array}{c}1 \\
14,3 \%\end{array}$ & $\begin{array}{c}2 \\
28,6 \%\end{array}$ & $\begin{array}{c}1 \\
14,3 \%\end{array}$ & - & - & $\begin{array}{c}1 \\
14,3 \%\end{array}$ & $\begin{array}{c}2 \\
28,6 \%\end{array}$ & $\begin{array}{c}7 \\
12,5 \%\end{array}$ \\
\hline 4. A humilhação por que passou & - & - & - & $\begin{array}{c}4 \\
66,7 \%\end{array}$ & - & - & - & $\begin{array}{c}1 \\
16,7 \%\end{array}$ & $\begin{array}{c}1 \\
16,7 \%\end{array}$ & $\begin{array}{c}6 \\
10,7 \%\end{array}$ \\
\hline 5. Outros & - & - & $\left|\begin{array}{c}2 \\
33,3 \%\end{array}\right|$ & - & - & $\begin{array}{c}1 \\
16,7 \%\end{array}$ & - & $\begin{array}{c}1 \\
16,7 \%\end{array}$ & $\begin{array}{c}2 \\
33,3 \%\end{array}$ & $\begin{array}{c}6 \\
10,7 \%\end{array}$ \\
\hline 6. O fato de ter usado drogas & - & $\begin{array}{c}2 \\
50,0 \%\end{array}$ & - & - & - & - & - & - & $\begin{array}{c}2 \\
50,0 \%\end{array}$ & $\begin{array}{c}4 \\
7,1 \%\end{array}$ \\
\hline 7. O roubo do qual foi vítima & - & - & - & - & - & $\begin{array}{c}1 \\
33,3 \%\end{array}$ & $\begin{array}{c}1 \\
33,3 \%\end{array}$ & $\begin{array}{c}1 \\
33,3 \%\end{array}$ & - & $\begin{array}{c}3 \\
5,4 \%\end{array}$ \\
\hline 8. As características próprias ou da vítima & - & - & - & - & - & - & - & - & $\begin{array}{c}1 \\
100 \%\end{array}$ & $\begin{array}{c}1 \\
1,8 \%\end{array}$ \\
\hline Total de justificativas & $\begin{array}{c}9 \\
16,1 \%\end{array}$ & $\begin{array}{c}2 \\
3,6 \%\end{array}$ & $\begin{array}{c}5 \\
8,9 \%\end{array}$ & $\begin{array}{c}13 \\
23,2 \%\end{array}$ & $\begin{array}{c}4 \\
7,1 \%\end{array}$ & $\begin{array}{c}5 \\
8,9 \%\end{array}$ & $\begin{array}{c}2 \\
3,6 \%\end{array}$ & $\begin{array}{c}5 \\
8,9 \%\end{array}$ & $\begin{array}{c}11 \\
19,6 \%\end{array}$ & $\begin{array}{c}56 \\
100 \%\end{array}$ \\
\hline
\end{tabular}

Nota. Legenda: J1 - Porque precisava defender a própria vida ou de familiares; J2 - Porque havia usado drogas; J3 - Por causa do sentimento que experienciou; J4 - Por causa da humilhação por que passou; J5 - Porque não encontrou alternativa; J6 - Porque queria vingar-se; J7 - Por causa de características próprias ou da vítima; J8 - Outros; J9 - Não justificou. 
Constatamos que são principalmente duas as razões dos entrevistados para terem cometido um homicídio: 'a agressão física que sofreu', 30,4\% e 'a defesa da própria vida ou de familiares', 2 1,4\%. Vejamos, então, quais foram as justificativas relacionadas a essas categorias de respostas.

Quando o motivo foi 'a agressão física que sofreu', houve uma tendência maior $(41,2 \%)$ para a justificativa 'por causa da humilhação por que passou'. Daqueles que responderam que o motivo para cometer o homicídio foi 'a defesa da própria vida ou de familiares’, $66,7 \%$ justificaram dessa forma 'porque precisavam defender a própria vida ou de familiares'.

Quando perguntamos sobre os motivos que tiveram para ter cometido o homicídio (JRR) no passado, pudemos constatar que os participantes nos forneceram 44 respostas, que foram agrupadas nas sete opções que podemos observar na Tabela 2, com as respectivas justificativas desses motivos, descritas na legenda.

Verificamos que o motivo que se destacou nas respostas dos entrevistados foi 'a agressão física que sofreu' $(34,1 \%)$. Os entrevistados justificaram esse motivo como suficiente para terem cometido o crime, principalmente: "porque queria vingar-se' (20\%) e 'por causa de características próprias ou da vítima' (20\%). São exemplos de justificativas que foram categorizadas nesta última opção: 'porque era mais novo e somente a sua vida era o que importava', 'porque nunca aceitou sofrer agressão física' e 'porque a vítima não valia nada'.
Ao compararmos os juízos de representação da realidade (JRR) da motivação para o homicídio, no presente e no passado, percebemos que 'a agressão física que sofreu' foi a resposta mais mencionada. Quanto às justificativas para esse motivo mais mencionado, percebemos que houve variação nos dois períodos de tempo investigados. Assim, as justificativas relacionadas a episódios de humilhação ("por causa da humilhação por que passou') são mais incidentes nas repostas do presente, como podemos observar no exemplo a seguir (utilizamos, no início de cada citação, entre parênteses, o nome fictício e a idade do entrevistado, com destaque para a sua fala):

(Carlos, 45 anos de idade) - O que você está chamando de humilhação? Você já pensou, no meio de 120 pessoas, alguém chegar e bater na senhora? Não é muita humilhação? . . To To mundo viu eu apanhando, e depois, a gente vai ficar como o quê? A gente vai ficar, como diz o outro, como "balaio de quitanda" na mão dos outros. .. Saco de pancada. Qualquer um pode querer "fazer hora com a minha cara". . I Isso aconteceu com você? Não chegou a acontecer. Só aconteceu com esse camarada. Ele só fez uma vez. . . Então, antes que acontecesse, naquele tempo da ignorância. . . a gente quer ter honra. Então o fato de ter matado alguém dentro do presídio, fez com que você tivesse honra perante os outros? Exatamente.

Já na época do crime as justificativas para este mesmo motivo, 'a agressão física que sofreu', giram em torno:

1. De vingança ('Porque queria vingar-se'):

Tabela 2

Distribuição das Respostas e das Justificativas dos Participantes para o JRR da Motivação no Passado

\begin{tabular}{|c|c|c|c|c|c|c|c|c|c|c|}
\hline \multirow{2}{*}{ Motivos do crime } & \multicolumn{9}{|c|}{ Justificativas } & \multirow{2}{*}{$\begin{array}{l}\text { Total de } \\
\text { respostas }\end{array}$} \\
\hline & $\mathrm{J}_{1}$ & $\mathrm{~J} 2$ & J3 & $\mathrm{J} 4$ & $\mathrm{~J} 5$ & $\mathrm{~J} 6$ & $\mathrm{~J} 7$ & $\mathrm{~J} 8$ & J9 & \\
\hline 1. A agressão física que sofreu & - & - & $\begin{array}{c}1 \\
6,7 \%\end{array}$ & $\begin{array}{c}2 \\
13,3 \%\end{array}$ & $\begin{array}{c}1 \\
6,7 \%\end{array}$ & $\begin{array}{c}3 \\
20,0 \%\end{array}$ & $\begin{array}{c}3 \\
20,0 \%\end{array}$ & $\begin{array}{c}2 \\
13,3 \%\end{array}$ & $\begin{array}{c}3 \\
20,0 \%\end{array}$ & $\begin{array}{c}15 \\
34,1 \%\end{array}$ \\
\hline 2. Outros & - & - & $\begin{array}{c}3 \\
30,0 \%\end{array} \mid$ & $\begin{array}{c}1 \\
10,0 \%\end{array}$ & - & $\begin{array}{c}2 \\
20,0 \%\end{array}$ & - & $\begin{array}{c}3 \\
30,0 \%\end{array}$ & $\begin{array}{c}1 \\
10,0 \%\end{array}$ & $\begin{array}{c}10 \\
22,7 \%\end{array}$ \\
\hline 3. A defesa da própria vida ou de familiares & $\begin{array}{c}5 \\
71,4 \%\end{array}$ & - & - & - & $\begin{array}{c}1 \\
14,3 \%\end{array} \mid$ & - & - & - & $\begin{array}{c}1 \\
14,3 \%\end{array}$ & $\begin{array}{c}7 \\
15,9 \%\end{array}$ \\
\hline 4. A humilhação por que passou & - & - & - & $\begin{array}{c}3 \\
75,0 \%\end{array}$ & - & $\begin{array}{c}1 \\
25,0 \%\end{array}$ & - & - & - & $\begin{array}{c}4 \\
9,1 \%\end{array}$ \\
\hline 5. O fato de ter usado drogas & - & $\begin{array}{c}2 \\
66,7 \%\end{array}$ & - & - & - & - & - & - & $\begin{array}{c}1 \\
33,3 \%\end{array}$ & $\begin{array}{c}3 \\
6,8 \%\end{array}$ \\
\hline 6. As características próprias ou da vítima & - & - & - & - & - & - & $\begin{array}{c}3 \\
100 \%\end{array}$ & - & - & $\begin{array}{c}3 \\
6,8 \%\end{array}$ \\
\hline 7. O sentimento que experimentou & - & - & - & - & - & - & - & $\begin{array}{c}1 \\
50,0 \%\end{array}$ & $\begin{array}{c}1 \\
50,0 \%\end{array}$ & $\begin{array}{c}2 \\
4,5 \%\end{array}$ \\
\hline Total de justificativas & $\begin{array}{c}5 \\
11,4 \%\end{array}$ & $\begin{array}{c}2 \\
4,5 \%\end{array}$ & $\begin{array}{c}4 \\
9,1 \%\end{array}$ & $\begin{array}{c}6 \\
13,6 \%\end{array}$ & $\begin{array}{c}2 \\
4,5 \%\end{array}$ & $\begin{array}{c}6 \\
13,6 \%\end{array}$ & $\begin{array}{c}6 \\
13,6 \%\end{array}$ & $\begin{array}{c}6 \\
13,6 \%\end{array}$ & $\begin{array}{c}7 \\
15,9 \%\end{array}$ & $\begin{array}{c}44 \\
100 \%\end{array}$ \\
\hline
\end{tabular}

Nota. Legenda: J1 - Porque precisava defender a própria vida ou de familiares; J2 - Porque havia usado drogas; J3 - Por causa do sentimento que experienciou; J4 - Por causa da humilhação por que passou; J5 - Porque não encontrou alternativa; J6 - Porque queria vingar-se; J7 - Por causa de características próprias ou da vítima; J8 - Outros; J9 - Não justificou. 
(Adriano, 45 anos de idade) - Naquela época, qual razão fez você matar aquele rapaz? ... ele me deu um soco e quando eu fui para cima dele, ele me mostrou a arma que estava na cintura e disse que da próxima vez a usaria. . . O que esta situação representou para você? Muita revolta. . Dá revolta em qualquer pessoa, você sangrando e não poder se defender? .. . a pessoa fica fora de si. . a a gente fica estranho, o sangue sobe à cabeça! É um fato esquisito. Eu fiquei cego naquela hora e disse 'isso não vai ficar assim não!' Por quê? Porque deu uma diferença para ele, e eu queria ir 'às forras'. .. teria que fazer com ele a mesma coisa que ele tinha feito comigo.

2. Das características do transgressor ('Por causa de características próprias'):

(Joaquim, 43 anos de idade) - Naquela época, qual foi seu motivo para matar aquele rapaz? ... Eu pensava 'eu vou matá-lo porque ele bateu em mim'. E por que o fato de ele bater em você, naquela época, era motivo para matá-lo? Porque eu era mais novo e não pensava muito na vida, não! A gente quando está mais novo, a gente faz tudo quanto é coisa, não pensa na vida direito. Você faz coisas sem pensar... Por que o fato de ele ter lhe batido era suficiente para você matá-lo? A gente é tão novo que não tem muito amor na família da gente! Eu tinha amor somente à minha vida. Naquela época somente a minha vida era o que importava. Só pensava em mim, daí o cara me bateu e eu tinha que matá-lo mesmo. Por quê? Eu não apanho não!

Sobre o juízo de valor moral (JVM) da motivação para o crime, no presente, verificamos que $80,6 \%$ das respostas dos participantes se referem ao motivo que tiveram para matar como sendo algo 'errado'. Quanto às suas justificativas para esses juízos, verificamos que $40 \%$ julgam dessa forma 'por causa das conseqüências (negativas)' e 20\% 'por causa de motivos religiosos'.

Perguntamos se haveria então outros motivos, que não os que eles tiveram, pelos quais pudessem justificar o crime cometido, e verificamos que aqueles que responderam 'Sim' a essa pergunta representam $63,6 \%$ da amostra. Assim, nesses casos, averiguamos que, mesmo que julguem como errados os motivos que tiveram, a maior parte dos participantes conseguem atualmente imaginar outros motivos, pelos quais também poderiam ter cometido o homicídio. Neste caso, investigamos quais seriam esses motivos e obtivemos que os mais citados foram 'o querer vingar-se', com 42,9\% de respostas e 'a defesa da própria vida ou de familiares', também com $42,9 \%$.

Ressaltamos que, dos que alegaram 'o querer vingar-se' como um motivo suficiente, $33,3 \%$ o fizeram 'por causa do sentimento que vivenciariam'. São exemplos de justificativas que foram categorizadas neste item que trata dos sentimentos: 'porque ama demais seu pai e não agüentaria qualquer coisa que fosse feita contra ele' e 'porque sentiria ódio de quem fizesse uma violência sexual contra um filho ou a esposa'. Aqui, este último resultado nos aponta para o fato de os sentimentos estarem associados aos crimes por vingança. Podemos estabelecer aqui uma possível relação entre essas duas situações: os sentimentos como motivadores para o crime de homicídio e os episódios de vingança, articulação que, obviamente, merece maior aprofundamento.
Quando investigamos o juízo de valor moral (JVM) da motivação no passado, constatamos que 70,6\% dos juízos apresentados pelos entrevistados foram considerados corretos. As justificativas que mais apareceram para este tipo de juízo foram: 'por causa de características próprias ou da vítima' (29,2\%), 'por causa da humilhação por que passou' $(25 \%)$ e 'porque precisava defender a própria vida ou de familiares' (20,8\%).

Ao compararmos os resultados encontrados sobre o JVM da motivação, no tempo presente e no tempo passado, verificamos que a incidência das respostas se apresenta de forma inversa. Assim, enquanto a maioria das respostas dos entrevistados $(80,6 \%)$ apontam para um juízo considerado errado diante dos motivos que tiveram para cometer o homicídio, no presente, a maioria delas $(70,6 \%)$ se referiam, à época do crime, aos motivos que tiveram como sendo corretos.

Sobre as justificativas para essas respostas, verificamos que, na época do homicídio, a maior parte julgou o motivo como correto, tendo em vista as justificativas:

1. 'Por causa de características próprias' (29,2\%):

(Fábio, 36 anos de idade) - Naquela época, achou certo esse motivo que você teve (da traição)? Naquela época tudo o que eu fazia eu achava que era certo. Por que achou certo? Porque eu era novo ainda e não tinha muito juízo. Não tinha mulher, não tinha filho, somente tinha minha mãe, que me dava de tudo.. . Tudo por causa da falta de responsabilidade. Eu não tinha responsabilidade nenhuma dentro de casa. . . Naquela época você achou certo o motivo do crime? É. Não tinha compromisso com nada. Não tinha nada para fazer na vida. Hoje tenho medo da cadeia também.

2. 'Por causa da humilhação por que passou' (25\%):

(Lucas, 30 anos de idade) - Como você julgou naquela época, esse motivo que teve? Na época eu achei que o motivo era certo. . . Por quê? Porque ninguém gosta de ser humilhado não! Homem nenhum gosta disso. . eu nunca tinha ouvido nem boatos de alguém que tivesse jogado droga na cara de alguém, aquilo foi muito desrespeito, ela tinha que morrer mesmo. E se ela tivesse feito isso, mas os dois rapazes não estivessem presenciando? ... Então a humilhação para mim já não seria tanta porque na frente de dois caras o que ela quis foi me botar para baixo, mas sozinha não! . . Se os caras não estivessem ali, naquela hora, não teria acontecido nada disso, eu teria deixado para lá. Mas na frente dos dois, ela quis se mostrar a 'maioral'.

3. 'Porque precisava defender a própria vida ou de familiares' $(20,8 \%)$ :

(Jonas, 42 anos de idade) - E naquela época você achou certo o motivo que teve para matá-lo? ... Na hora o que a gente quer fazer é tentar defender contra o pior. . Você achava que a razão de proteger a sua irmã era um motivo certo? Não é isso! Eu tentei evitar, tentar barrar ele para não alcançar minha irmã. Eu pulei na frente dele para evitar, mas ele me agrediu. Foi daí que aconteceu isso. Você acha que o atacou porque ele te agrediu? Não, se ele para e me atende, não teria acontecido! . . . Mas houve aquele momento de ele me agredir... e então, na hora que eu vi que era uma faca, foi o que me veio na mente naquela hora, eu pensei 'eu tenho que me defender'. E esse motivo de se defender, você achou certo, naquela época? ... Naquele dia, para falar a verdade, eu achei certo eu me defender. Claro, ninguém quer morrer. . 
Por outro lado, atualmente, a maior parte julga como errado o motivo que teve, principalmente:

1. 'Por causa das conseqüências negativas' ( $40 \%)$ :

(João, 40 anos de idade) - Você acha, hoje, certos estes motivos que teve? ... são dois pesos! Eu defendi a minha vida e a integridade da minha filha e da minha esposa, entendeu? Ao mesmo tempo eu tinha uma vida organizada, equilibrada e perdi tudo. . . Mas pensando hoje, sobre este motivo, você acha que ele é certo? Não. Por quê? Eu acho que, quer queira, quer não, é um trauma que vou carregar para o resto de minha vida. Qual é este trauma? De meu filho crescer comigo dentro da cadeia. . . o trauma de. . meus filhos saberem que o papai matou o fulano! E eu acho que um pai de família tem que ter um exemplo a dar. . Foi horrível. Passei por uma situação de tortura na vida e para quem sempre trabalhou... acho que não merecia isto não.

\section{2. 'Por causa de motivos religiosos' (20\%):}

(Carlos, 45 anos de idade) - Você acha certo o motivo que teve (ter apanhado) para tê-lo matado? Não. Por quê? ... Porque hoje sou uma pessoa diferente. . . hoje sou um cristão. Vejo o lado das pessoas. Depois que eu aceitei Jesus, eu já sofri troço pior do que aquilo e nunca levantei uma palha para o camarada. . Não sou aquela pessoa ignorante de antes, porque o senhor é que toma conta ... A partir do dia em que nós abandonamos aquela vida velha e procuramos, na igreja, a seguir o seu próprio Jesus, nós esquecemos tudo aquilo que uma pessoa faz com a gente, de errado. Então a nossa obrigação à partir do dia em que nós levantamos uma mão a aceitamos o senhor como o salvador, é nos humilhar como Jesus se humilhou.

É interessante notar que atualmente os participantes parecem ter modificado seu juízo de valor sobre o motivo que tiveram, principalmente pelas consequiências negativas, as mais diversas, sobretudo para si e para os próprios familiares, após o acontecimento do homicídio. Exemplificamos essas consequiências com algumas das justificativas constantes de seus relatos: 'porque sofreu muito', 'porque complicou a vida', 'porque estragou a vida', 'porque foi muito humilhado na prisão', porque carregou um peso em sua consciência pelo que cometeu' e 'porque sua família sofreu muito'. Nesse sentido, esse resultado aponta para a hipótese de que, então, se não houvesse perdas para o sujeito transgressor, ele não teria mudado seu juízo sobre o motivo que teve, após o tempo transcorrido, que foi o foco de nossa investigação. Ressaltamos que os entrevistados que ficaram encarcerados apontam, via de regra, as conseqüências ruins que sofreram após o crime cometido, quando lhes foi retirada sua liberdade. No entanto, aqueles que permaneceram em liberdade após o crime, que foram cinco participantes, também mencionam conseqüências negativas, embora diferentes das dos primeiros, como, por exemplo, o fato de ficarem estigmatizados como criminosos na sociedade.

Por outro lado, notamos que a justificativa 'por causa de motivos religiosos' ocorre somente no presente, pois os entrevistados sugerem ter modificado seu juízo de valor acerca do motivo, justamente por causa de uma experiência religiosa que não possuíam antes do crime. Sabemos da grande inserção de crenças religiosas (variadas) nos presídios, o que ocasiona para muitos internos uma possibilidade de se vincularem a alguma delas e de seguirem os seus ensinamentos após a liberdade condicional. Por esse tipo de justificativa, podemos pensar que, mesmo não tendo havido perdas para aqueles que cometeram o crime de homicídio, uma parcela deles poderia ainda ter modificado seu juízo de valor acerca do motivo que teve, em função de uma escolha religiosa, que os faria perceber diferentemente o que fizeram, passado esse período de tempo. Diante dessa discussão vemos a necessidade de outras pesquisas que possam abordar especificamente essa possível relação entre a religião e o juízo de valor moral.

De qualquer forma, constatamos que uma mudança no juízo de valor moral da motivação para o crime, na história desses participantes, depende de dois fatores distintos: passam a pensar em si mesmos, fundamentalmente, avaliando o quanto tirar a vida de alguém os prejudicou; passam a mencionar razões religiosas, já se referindo ao valor da vida, ao relatarem que somente Deus poderia tirar a vida, deixando assim de se considerarem somente a si mesmos. Portanto, sempre que os participantes passam a julgar os motivos para o homicídio como errados, em função apenas das consequêencias ruins que tal fato lhes acarretou, tendem a considerar outros motivos pelos quais também teriam matado a vítima. Ao contrário, quando a mudança de posição nesse juízo se justifica por razões religiosas ou pelo valor que passaram a atribuir à vida, nenhum outro motivo alegam como possibilidade de justificativa para o crime que cometeram.

\section{Considerações Finais}

Chamamos a atenção para os resultados que puderam ser analisados levando-se em conta tanto o JRR quanto o JVM da motivação, de uma forma concomitante. Assim, discutiremos as fundamentações pertinentes a situações de humilhação, vividas pelos transgressores antes de cometerem o homicídio. Esse fato ocorreu com relação ao JRR da motivação, somente no presente, e com relação ao JVM da motivação, sempre que o assunto era pesquisado com foco na época do crime, ou seja, no passado. Dessa forma, a justificativa 'Por causa da humilhação por que passou' foi alegada por alguns dos entrevistados, no presente, para fundamentar os motivos que tiveram para ter matado alguém, e, por outros, sempre no passado, para fundamentar o fato de considerarem corretas as razões que tiveram para o homicídio.

Ainda sobre essas justificativas que tratam de situações de humilhação, verificamos que elas apareceram de duas formas distintas para esses participantes, quando comparamos o presente com o passado. Assim, sempre que a justificativa 'por causa da humilhação por que passou' aparece para fundamentar as respostas de questões investigadas no passado, vemos que a humilhação vivida pelos transgressores, antes do crime cometido, fez com que eles reagissem cometendo o homicídio, ou seja, eles agiram 'pela honra', diante daquelas situações. Vejamos alguns exemplos sobre essas justificativas para o JVM da motivação, no passado: 'porque 
era preciso manter o nome de homem', 'porque se sentiu desrespeitado', 'porque foi desrespeitado e tinha que revidar matando', 'porque um homem não deve apanhar'. Quando tratamos do presente, essas justificativas também podem ser vinculadas ao agir 'pela honra', como acima, como constatamos no JRR da motivação, no presente: 'para provar que era homem e ser respeitado', porque não se deve bater em cara de homem', 'porque, se não reagisse à agressão física, seria um covarde', 'porque o povo debocha de quem sofre agressão física e não faz nada'. Assim, seja no passado seja no presente, essa justificativa está relacionada ao fato de os sujeitos mencionarem as questões estudadas como corretas.

Consideramos importante acrescentar um questionamento que La Taille (2002) faz, ao dar o seguinte exemplo: seria possível a algum homem de nossa cultura não ter o atributo da virilidade ligado à sua imagem, sendo pertencente ao gênero masculino? E mais: “. . . se for verdade que cada homem, mesmo à sua revelia, vê-se como 'viril' do ponto de vista físico, então entre as suas 'boas imagens' encontra-se aquela do 'macho'." (p. 95). Neste caso, os sujeitos do gênero masculino sentir-se-ão, via de regra, ofendidos, insultados, humilhados sempre que sua masculinidade for atingida, tendo em vista o valor que está vinculado à sua honra, que é a idéia de que homem não apanha.

Por outro lado, no presente, as fundamentações relacionadas à humilhação podem aparecer vinculadas à justificativa 'por causa das conseqüências (negativas ou positivas)' e, nesse caso, está vinculada ao juízo que os participantes formulam nessas situações, ou seja, julgam-nas como erradas. Nesse caso, alguns entrevistados julgaram errados os motivos que tiveram para o homicídio. A humilhação é aqui abordada pelos sujeitos após terem cometido o homicídio, na situação de seu aprisionamento, e é justamente em decorrência disso que passam a mencionar a humilhação vivida como uma conseqüência negativa do crime cometido, que está, por essa razão, vinculada ao juízo que manifestam sobre essas questões estudadas, como sendo 'Errado'.

Por fim, destacamos duas discussões suscitadas a partir dos resultados encontrados no JVM e que dizem respeito, respectivamente, à reincidência criminal e à punição e educação moral, como práticas da instituição carcerária. Apesar de, no presente, alguns sujeitos terem julgado como errado o motivo que tiveram para matar 'por causa das conseqüências negativas' ou 'por causa de motivos religiosos', não podemos afirmar que esses argumentos seriam suficientes para evitar a reincidência (um agir novamente, praticando outro homicídio), pois dizem respeito a raciocínios morais (juízos) e não a condutas. Essa é uma das questões teóricas fundamentais na área de estudo da moralidade, que é a relação existente entre raciocínio moral e conduta moral, e vários autores (Blasi, 1980; Kupfersmid \& Wonderly, 1980; Mwamwenda, 1992) têm defendido a posição de que parece não haver ainda uma relação claramente delimitada entre ambos os aspectos.

Embora punição e educação religiosa, ambas relacionadas com a época do encarceramento, sejam para alguns sujeitos o que fundamentalmente possibilitou mudanças em seus juízos (quando tratam do assunto no passado e no presente), não podemos afirmar que essas práticas sejam de fato responsáveis por mudanças de valores morais. No entanto, consideramos relevantes os estudos nessa direção, que averigúem a existência desses indícios nas ações da instituição carcerária, seja por meio de uma investigação da própria instituição e de suas ações, seja a partir dos juízos que os sujeitos, internos ou egressos, possuam a respeito das ações da instituição.

Embora nos tenhamos detido somente nos juízos de representação da realidade e de valor moral da motivação dos participantes, cientes, contudo, da necessidade de uma compreensão mais ampla dos aspectos abordados sobre o sujeito homicida, acreditamos que os resultados encontrados possam fornecer subsídios para um melhor conhecimento da população aqui investigada. Esperamos que as discussões aqui propostas possibilitem a elaboração de ações que melhorem o atendimento, por parte das instituições públicas, àqueles que lhes são encaminhados após o cometimento de um homicídio. Nutrimos ainda a expectativa de poder, de alguma forma, colaborar para a consecução de um dos principais objetivos dessas instituições, qual seja, o de evitar a reincidência do infrator no crime, pois acreditamos que essa compreensão do sujeito homicida, ainda que parcial, possa contribuir nessa tarefa. Vale dizer, sem essa compreensão do sujeito transgressor é improvável qualquer pretensão de resgatá-lo do contex to da criminalidade.

\section{Referências}

Ades, L. (1999). Em nome da honra: Reações a uma situação de humilhação. Dissertação de Mestrado não-publicada, Universidade de São Paulo, SP.

Adorno, S. (1998). Conflitualidade e violência. Tempo Social: Revista de Sociologia da USP, 1O(1), 19-47.

Alencar, H. M. (2003). Parcialidade e imparcialidade no juízo moral: Gênese da participação em situações de humilhação pública. Tese de Doutorado não-publicada, Universidade de São Paulo, SP.

Aranha, A. J. Q. T. C. (1995). Crimes contra a honra. São Paulo, SP: Saraiva.

Blasi (1980). Bridging moral cognition and moral action: A critical review of the literature. Psychological Bulletin, 88(1), 1-45.

Brasil (1997). Código Penal. São Paulo, SP: Revista dos Tribunais.

Chauí, M. (1980). A não violência do brasileiro, um mito interessantíssimo. Almanaque: Cadernos de Literatura e Ensaio, 11, 16-24.

Delval, J. (2002). Introdução à prática do método clínico: Descobrindo o pensamento das crianças (F. Murad, Trad.). Porto Alegre, RS: Artmed.

Febvre, L. (1998). Honra e pátria (E. Aguiar, Trad.). Rio de Janeiro, RJ: Civilização Brasileira.

Kant, I. (1980). Fundamentação da metafísica dos costumes (P. Quintela, Trad.). In Os pensadores (Vol. 2, pp. 101-162). São Paulo, SP: Abril Cultural. (Original publicado em 1785)

Kant, I. (1994). Crítica da razão prática (A. Morão, Trad.). Lisboa, Portugal: Edições 70. (Original publicado em 1788)

Kupfersmid, J. H., \& Wonderly, D. M. (1980). Moral maturity and behavior: Failure to find a link. Journal of routh and Adolescence, 9(3), 249-261. 
La Taille, Y. (1992). Desenvolvimento do juízo moral e afetividade na teoria de Jean Piaget. In Y. De La Taille., M. Kohl de Oliveira. \& H. Dantas (Eds.), Piaget, Vygotsky, Wallon: Teorias psicogenéticas em discussão (pp. 47-73). São Paulo, SP: Summus.

La Taille, Y. (1997). Para um estudo psicológico da honra. In L. Banks-Leite (Ed.), Percursos piagetianos (pp. 225-241). São Paulo, SP: Cortez.

La Taille, Y. (2002). Vergonha: A ferida moral. Petrópolis, RJ: Vozes.

Mello Jorge, M. H. P., Gawryszewski, V. P., \& Latorre, M. R. D. de O. (1997). Análise dos dados de mortalidade. Revista de Saúde Pública, 31(4), 5-25.

Mwamwenda, T. S. (1992). Moral development and behavior. Psychological Reports, 71(2), 499-502.

Piaget, J. (s.d.). Introdução: Os problemas e os métodos (R. Fiúza, Trad.). In A representação do mundo na criança (pp. 5-28). Rio de Janeiro, RJ: Record. (Original publicado em 1926)
Piaget, J. (1994). O juízo moral na criança (2. ed., E. Leonardon, Trad.). São Paulo, SP: Summus. (Original publicado em 1932) Velho, G. (1996a). Violência, reciprocidade e desigualdade: Uma perspectiva antropológica. In G. Velho \& M. Alvito (Eds.), Cidadania e violência (pp. 10-24). Rio de Janeiro, RJ: Editora da Universidade Federal do Rio de Janeiro.

Velho, G. (1996b). Debates: Violência e cultura, criminalidade e violência. In Velho, G. \& Alvito, M. (Eds.), Cidadania e violência (pp. 234-245, 265-289). Rio de Janeiro, RJ: Editora da Universidade Federal do Rio de Janeiro.

Zaluar, A. (1994). Condomínio do Diabo. Rio de Janeiro, RJ: Editora da Universidade Federal do Rio de Janeiro.

Zaluar, A. (1996). Da revolta ao crime S. A. São Paulo, SP: Moderna.

Recebido: $17 / 01 / 2005$ $1^{a}$ revisão: $12 / 12 / 2005$ Aceite final: $23 / 03 / 2006$ 